\title{
Characterization of Anopheline unique peroxidase and its role in the regulation of Plasmodium development
}

\author{
Mithilesh Kajla ${ }^{1 *}$, Parik Kakani', Tania Pal Choudhary', Kuldeep Gupta', Rini Dhawan', SK Gakhar², Lalita Gupta', \\ Sanjeev Kumar ${ }^{1}$
}

From Challanges in malaria research: Core science and innovation

Oxford, UK. 22-24 September 2014

\section{Background}

Malaria is major health problem in tropical and subtropical countries of the world. The WHO reported, 207 million malaria cases and 627,000 deaths in 2013 [1]. Malaria is caused by Plasmodium, which completes its asexual cycle in human host and sexual cycle in the female Anopheline mosquito. In order to combat malaria several strategies are in progress, blocking Plasmodium development inside mosquitos is one of them. For this transmission blocking approach we need to understand mosquito immune system and its interaction with Plasmodium at molecular levels. In the African malaria vector, Anopheles gambiae, a peroxidase HPX15 (IMPer) is reported to modulate mosquito immunity against Plasmodium [2]. Furthermore we are interested in understanding the regulation of Plasmodium development by its orthologous peroxidase-mediated immune responses in major Indian malaria vectors $A n$. stephensi and An. culicifacies.

\section{Materials and methods}

We took advantage of An. gambiae and other insects with known genomic sequences to explore the peroxidases of An. stephensi (AsP-15) and An. culicifacies (AcP-15). We amplified An. stephensi midgut and carcass cDNA with degenerate primers and the resulting $420 \mathrm{bp}$ fragment was cloned, sequenced and blasted to confirm its identity. Using gene specific primers, tissue-specific and developmental-specific expression as well as its immune role against bacteria, fungus and $P$. berghei was studied. Phylogenetic analysis was carried using Mega 5.02. Silencing of

${ }^{1}$ Molecular Parasitology and Vector Biology Laboratory, Department of Biological Sciences, Birla Institute of Science and Technology, Pilani,

Rajasthan, India

Full list of author information is available at the end of the article
AsP-15 in adult females was achieved by dsRNAi to confirm its role in immunity.

\section{Results}

Sequence analysis revealed a peroxidase, similar to HPX15 of An. gambiae, so it was named as AsP-15 and AcP-15 in An. stephensi and An. culicifacies, respectively. AsP-15 is induced in midgut after blood feeding and pupal stage of mosquito. It is inducing against bacterial and fungal elicitors. Phylogenetic analysis reveals that it is a unique peroxidase, which is evolutionary conserved among Anophelines.

\section{Conclusions}

AsP-15 is an ortholog of HPX15 and it may have a role in modulation of An. stephensi gut immunity against blood borne elicitors. Phylogenetic analysis reveals that HPX15, AsP-15 and AcP-15 are unique to Anophelines and this may be due to the involvement of this peroxidase in regulation of Plasmodium development.

\section{Acknowledgements \\ We acknowledge Department of Science \& Technology for the research grant and University Grant Commission for the fellowship. Special thanks to BITS-Pilani for providing the lab facility and Central Animal Facility for providing animals. \\ Authors' details \\ 'Molecular Parasitology and Vector Biology Laboratory, Department of Biological Sciences, Birla Institute of Science and Technology, Pilani, Rajasthan, India. ${ }^{2}$ Department of Life Sciences, Maharashi Dayanand University, Rohtak, Haryana, India.}

Published: 22 September 2014

\section{References}

1. WHO report. Geneva: WHO; 2013. 
2. Kumar S, Molina-Cruz A, Gupta L, Rodrigues J, Barillas-Mury C: A peroxidase/dual oxidase nsystem modulates midgut epithelial immunity in An. gambiae. Science 2010, 327:1644-1648.

doi:10.1186/1475-2875-13-S1-P49

Cite this article as: Kajla et al:: Characterization of Anopheline unique peroxidase and its role in the regulation of Plasmodium development. Malaria Journal 2014 13(Suppl 1):P49.

Submit your next manuscript to BioMed Central and take full advantage of:

- Convenient online submission

- Thorough peer review

- No space constraints or color figure charges

- Immediate publication on acceptance

- Inclusion in PubMed, CAS, Scopus and Google Scholar

- Research which is freely available for redistribution

Submit your manuscript at www.biomedcentral.com/submit
C) Biomed Central 